\title{
Are we reaching gender parity among Palaeontology authors?
}

\section{Summary}

We examine whether the proportion of women publishing in palaeontology is approaching parity, using data from the journal Palaeontology as a proxy for the discipline. This work was motivated by the sense that, despite increased representation of women, articles on palaeontological subjects almost never appear to have $50 \%$ female authorship, regardless of the journal. Indeed, we find that $<20 \%$ of authors are female, and perhaps more surprisingly, insubstantial increase in the proportion of women contributing to the journal over the past 20 years. We highlight important barriers that remain for women and other underrepresented groups in science, and we make several recommendations to help improve their representation in palaeontology.

\section{Background}

Women remain underrepresented in almost all areas of STEM, especially at senior levels, with palaeontology being no exception ${ }^{1}$. There is a widespread perception that the situation is improving (e.g. more than half of postgraduate students studying science in the UK are now women ${ }^{2}$ ), and that it is simply a matter of time before this improvement is reflected at higher career stages. However, the well-characterized "leaky pipeline" (the term used to describe the phenomenon of gender inequality persisting for much longer at senior career stages) suggests that further progress will be slow (Grogan 2018). Evidence that formidable barriers remain for women in palaeontology derives from a recent analysis of career prospects in palaeontology ${ }^{3}$, the results of the PalAss Diversity Study ${ }^{1}$, and the experiences of many women in the field. Underrepresentation of any group in the workforce matters, not only in the interests of fairness, but because diverse work environments are more productive, lead to better research, and are more inclusive in ways that benefit everyone (Berenbaum 2019; Fine and Sojo 2019). Therefore, we must question how much progress towards gender equality has been made in order to continue on a path towards equity. The extent to which circumstances are improving for any group of individuals in science can be hard to assess, partly due to the complex factors that ultimately lead individuals to make career choices. However, information and data are available, and it is essential that we try to utilise such data, both in regard to ensuring current policies and initiatives are effective, and as a starting point for identifying remaining barriers to inclusion.

\footnotetext{
$1<$ https://www.palass.org/association/diversity-study>

2 <https://www.hesa.ac.uk/data-and-analysis/students/whos-in-he>

3 <https://www.palass.org/publications/newsletter/long-term-career-prospects-phd-students-palaeontology>
} 
With a view to contributing quantitative data to this discussion in palaeontology, we take a look at the scientific output of men versus women in our field. If the gender balance in palaeontology has been shifting over time, we should expect to see this manifest across different metrics for measuring scientific productivity, including the number of peer reviewed publications. Publication-based metrics are important because they are used widely as a measure of scientific productivity, and ultimately determine whether an individual is employed, promoted or accoladed in academia. In this article, we examine the proportion of women publishing in the Association's flagship journal Palaeontology. Published work on gender-based publication biases consider much broader research areas (e.g. Earth ${ }^{4}$, physical or biological sciences; Bendels et al. 2018), and no data exist for publications that fall within the palaeontology or palaeobiology subdisciplines. Palaeontology is currently the most successful (in terms of impact factor and other metrics ${ }^{5}$ ) subject-specific palaeontological journal, and publishes broadly within the subject (e.g. both vertebrate and invertebrate work; descriptions and macroevolutionary studies). Our findings are therefore likely to reflect patterns across palaeontology more generally.

\section{Why might women remain underrepresented in the literature?}

There are many reasons women continue to remain underrepresented in the literature ${ }^{6}$ Within the context of academic publishing, women have been found to publish fewer papers and are less likely to be listed as first authors ${ }^{7}$, will have their papers cited less either by themselves or by others (Larivière 2013; King et al. 2017), are less likely to submit to high impact journals (Filardo et al. 2016; Mayer and Rathmann 2018; Shen et al. 2018), are less likely to be invited to peer review at all career stages (Lerback and Hanson 2017), including within Earth sciences ${ }^{8}$, are held to a higher standard (Knobloch-Westerwick 2013; Hengel 2017; Fox and Paine 2019), and are more likely to be pressured into adding co-authors (Fong 2017). They are also less likely to be invited to participate in seminars, conferences, and panels (Nittrouer et al. 2018). Within their institutes, women are also more likely to shoulder greater administrative and teaching responsibilities (Guarino and Borden 2017), and be paid less than their male counterparts. Women with childcare responsibilities are also less able to travel for work and presented with fewer networking opportunities.

Additional factors determining whether women stay in science long term include challenges associated with childcare responsibilities (in addition to travel), widespread sexual harassment

\footnotetext{
${ }^{4}<$ https://www.nature.com/articles/ngeo3026>

5 <https://sites.google.com/site/kennethdebaetswebpage/home/journals-in-paleontology-and-evolutionary-biology>

${ }^{6}<$ https://nplusonemag.com/issue-34/essays/sexism-in-the-academy/>

7 <https://www.elsevier.com/research-intelligence/campaigns/gender-17>

${ }^{8}<$ https://www.nature.com/articles/ngeo3026>
} 
and bullying within research institutes ${ }^{9}$, and the so-called 'subtle sexism' that women and girls experience in science and throughout their lives (Serio 2016). Until women are equally represented at all levels in research, we can expect to see inequality reflected in the literature.

\section{What proportion of female authors do we expect to see in palaeontology?}

We know fewer women than men are employed in long-term positions in palaeontology, and this disparity is anticipated in published-author gender ratios. A useful basis for comparison would therefore be the proportion of women actually employed in palaeontology. Data collected during the PalAss Diversity Study suggest that women make up $35 \%$ of individuals working in the field, with $80 \%$ of female respondents under 45 years of age. Age (a general proxy for career stage) of authors is important to consider, because women have been underrepresented historically within the Earth sciences. This means the proportion of women contributing to the literature is expected to be lowest among senior academics, which is commonly considered the most productive phase (in terms of publication output) of an individual's career. Even considering these factors, lack of change in the proportion of women contributing to palaeontology in recent decades might seem surprising -- especially among first authors, who are more likely to be at earlier career stages.

\section{Data and Methods}

Author information was downloaded from the Palaeontology journal website for all available articles, which span the interval 1957-2019, using the R packages xml2 and Rvest. Gender was predicted based on first names with the $\mathrm{R}$ package gender using three methods (= databases): ssa, ipums and napp. Gender was assigned using the most frequent value returned using the three methods, and uncertainty (the proportion of times that another gender was associated with a given name) was taken as the average across methods. Names that could not be assigned to either gender above the $80 \%$ confidence level were treated as "unknown". Most unknowns can be attributed to first names being represented in the database by initials only. We emphasise that our approach to gender assignment makes the assumption that gender is binary, which is not representative of the diversity of genders within the palaeontology community $^{1}$. Best practice would be to ask authors to self-declare their gender upon article submission, or to contact authors individually and ask them to report their gender or opt out of analyses, and we encourage this approach going forward. However, this methodology is not possible for analyses such as this, which uses historical data on a large scale. We also note that the name data in this package is based on US and Northern European census data, and thus a demographic bias will be introduced. No attempts were made to manually assign gender, in

\footnotetext{
${ }^{9}<$ https://1752group.files.wordpress.com/2018/09/silencing-students_the-1752-group.pdf>
} 
order to ensure the results are fully reproducible. We also note that such an approach in this instance would often be practically impossible (for example, where common initial and surname combinations occur). All code available to reproduce figures and tables is available online ${ }^{10}$.

As of 6th February 2020, the database contains 6,884 individual author entries across 3,319 unique articles, of which 4,400 were assigned a gender above the 0.8 confidence level (male = 3,557 , female $=843$ ). 2,241 articles have at least one gender-assigned author, 1,673 have 100\% gender-assigned authors.

\section{Overview of findings}

The data (Figures 1-5) indicate that the percentage of female authors contributing to the journal and the percentage of first authors that are female has increased over time, based on the total number of authors, including unknowns ${ }^{11}$. However, the overall increase is low and the percentage of female authors remains below $20 \%$. The percentage of articles that have over $50 \%$ female co-authorship remains unchanged. The proportion of articles that have no female authors is decreasing, but this partly reflects an increase in the average number of authors per article, which has increased from 1 to 3.5. The overall number of women publishing in palaeontology has increased, but this parallels an increase in the number of men. In other words, women may seem more prominent in palaeontology now simply because there are more total palaeontologists, but it does not follow that their relative proportion has also increased.

Our findings match the proportions of women publishing reported in broader studies of the scientific literature (Holman et al. 2018), which generally report $<40 \%$ in biological sciences and $<30 \%$ in the Earth sciences (e.g. Bendels et al. 2018). Studies that have examined temporal trends also report slow progress, with one study reporting $<1 \%$ increase in female authors each year (Shen et al. 2018). Progress with respect to other aspects of diversity, including representation of ethnicity and race, appear to be even worse, based on other metrics of scientific productivity (Bernard and Cooperdock 2018). Palaeontology is therefore not alone in underrepresenting women or other aspects of diversity, and faces the same challenges as other scientific journals. This, however, is not equivalent to saying there is nothing to be done to increase gender balance and, importantly, that initiatives that are shown to work in other disciplines are also likely to work in palaeontology.

\footnotetext{
${ }^{10}<$ https://bitbucket.org/rachelwarnock/diversity-study/>

${ }^{11}$ Note that anecdotal evidence suggests most unknowns are male, although the reason for this has changed over time. In the past, unknowns are mainly attributable to individuals publishing under their initials, who are more likely to be male. More recently, unknowns are attributable to non-European names that are less well represented in name databases, who are also more likely to be male.
} 


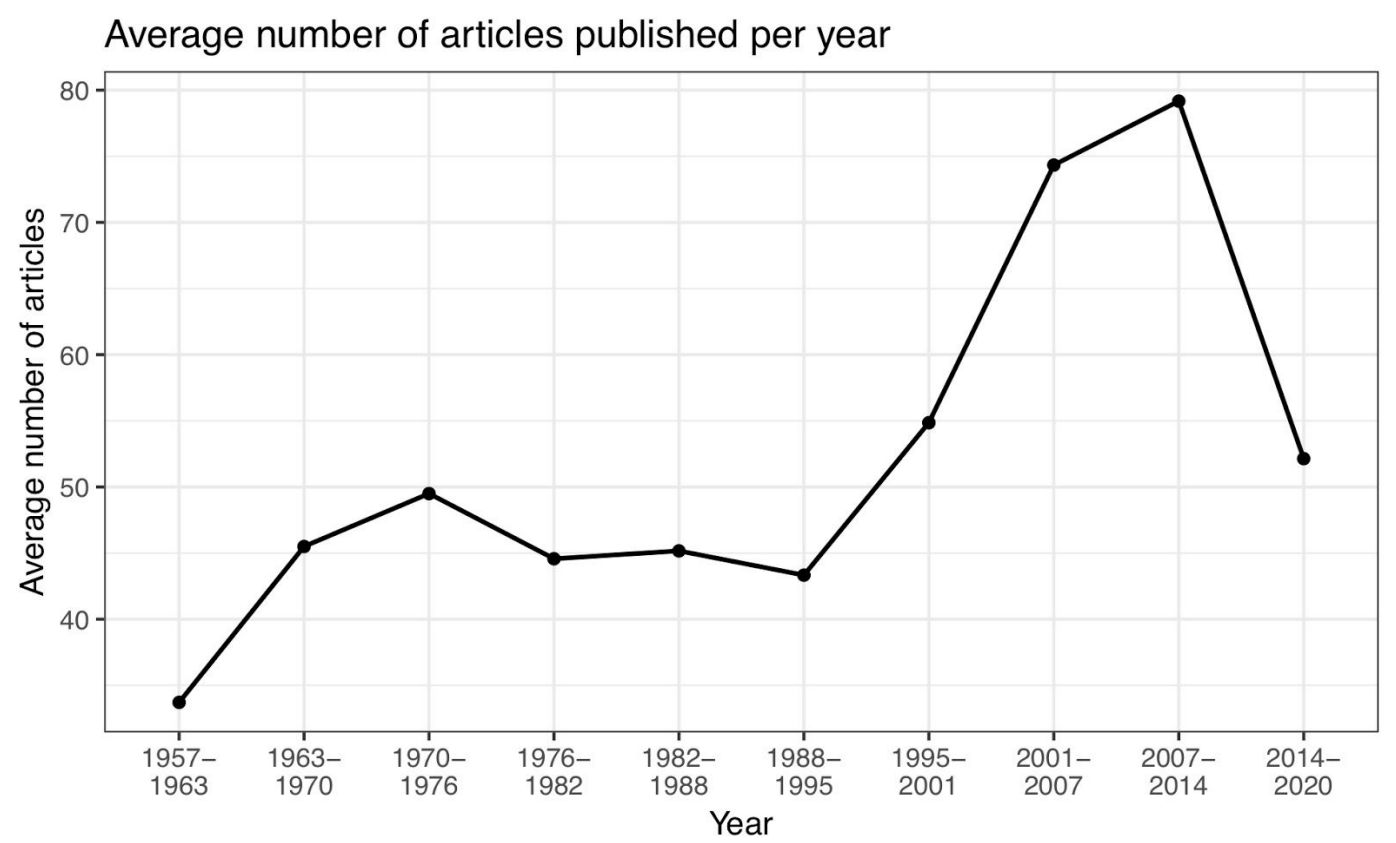

Figure 1. Average number of peer-reviewed articles published per year in Palaeontology.

Average number of authors per article

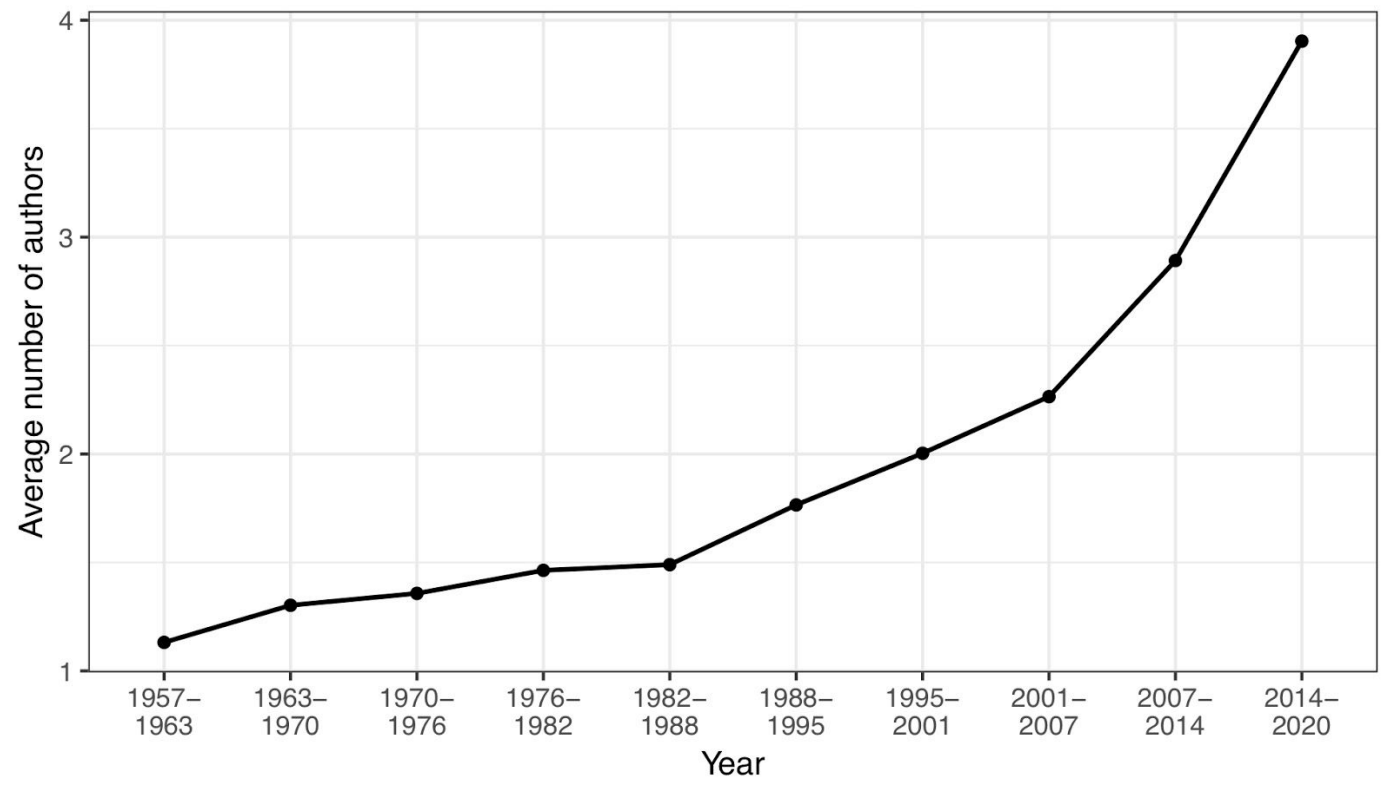

Figure 2. Average number of authors per article published in Palaeontology. 
Total number of male versus female authors

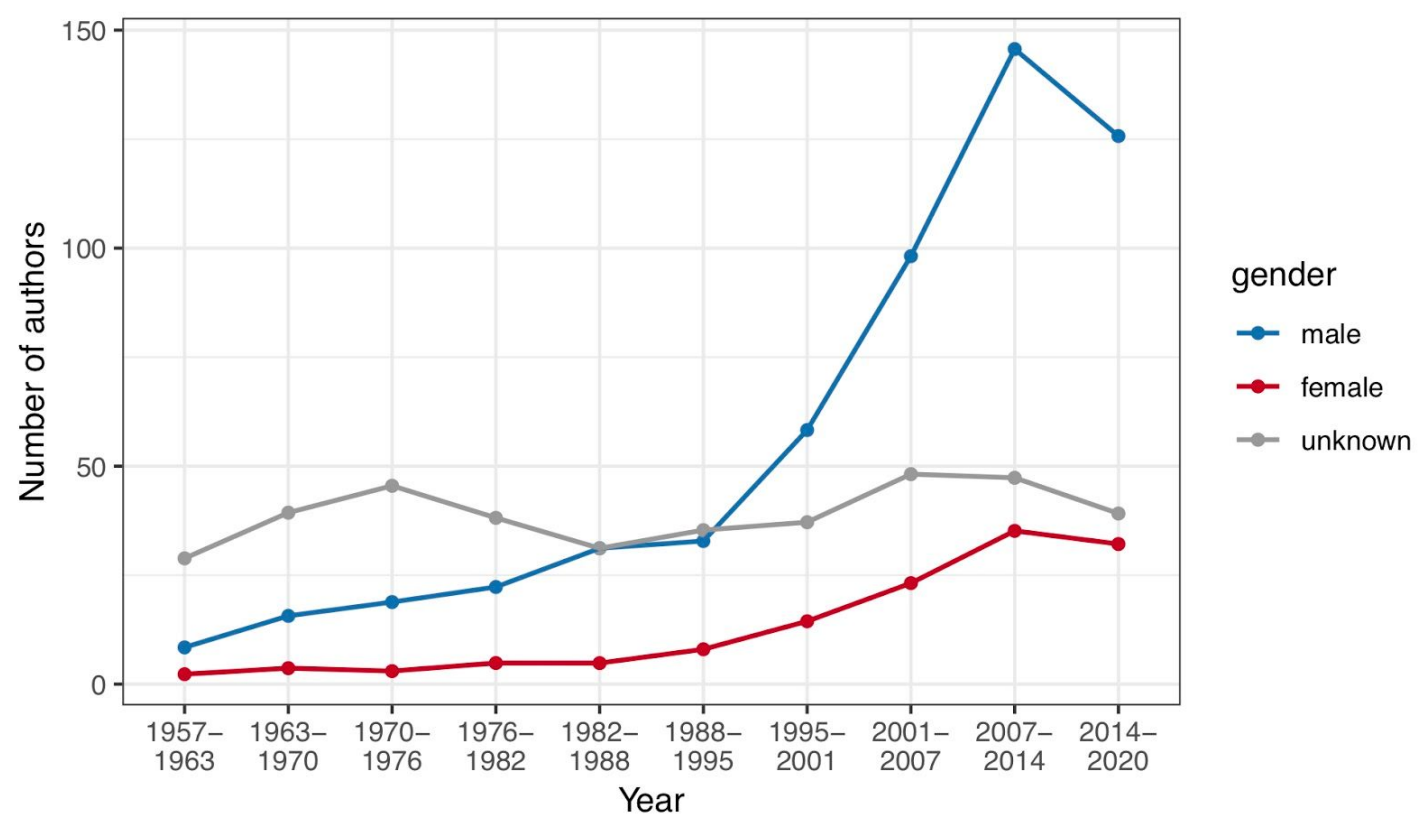

Figure 3. Total number of male versus female authors across all articles published in Palaeontology.

Percentage of female authors

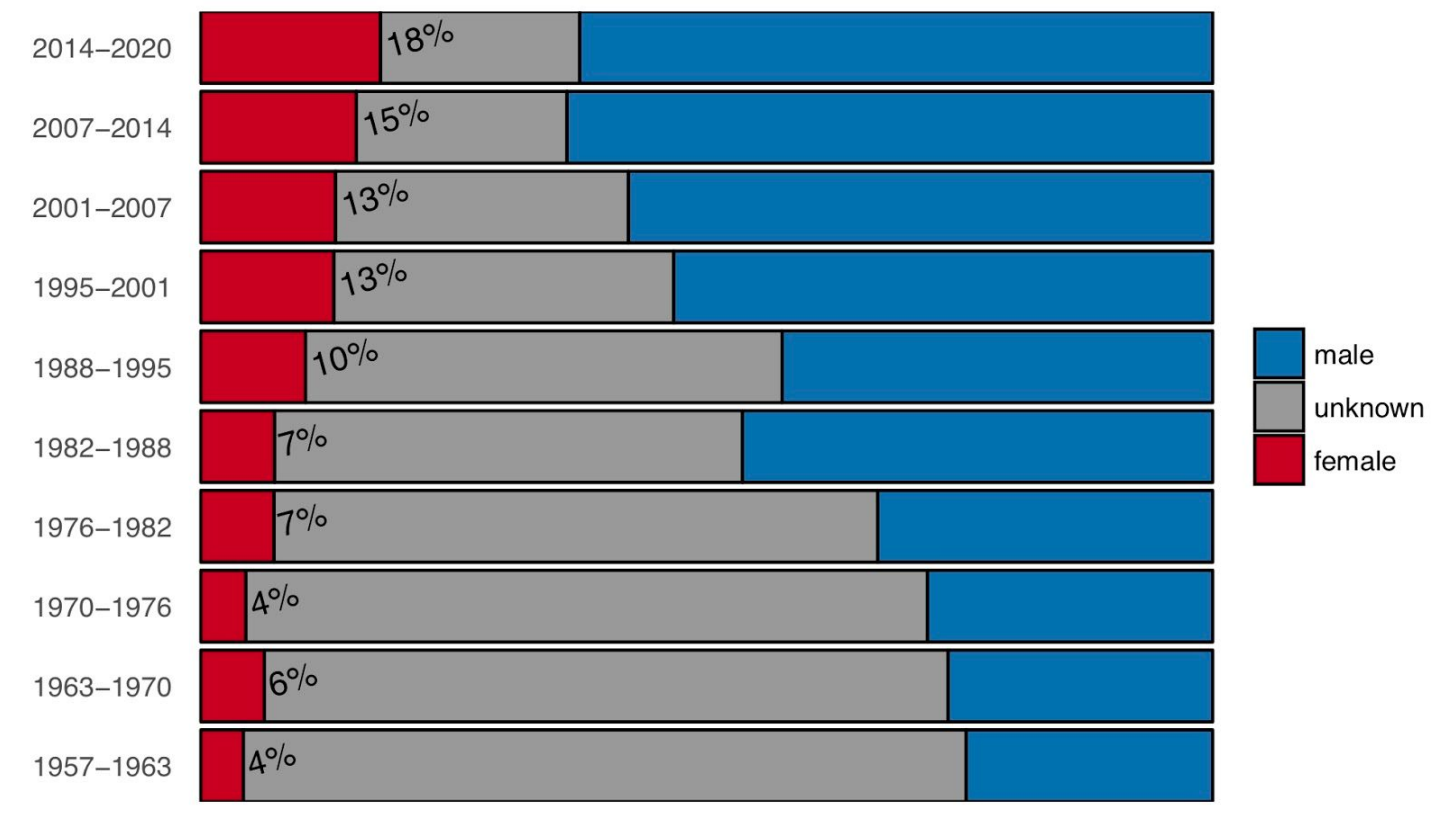

Figure 4. Percentage of male versus female authors across all articles published in Palaeontology. 


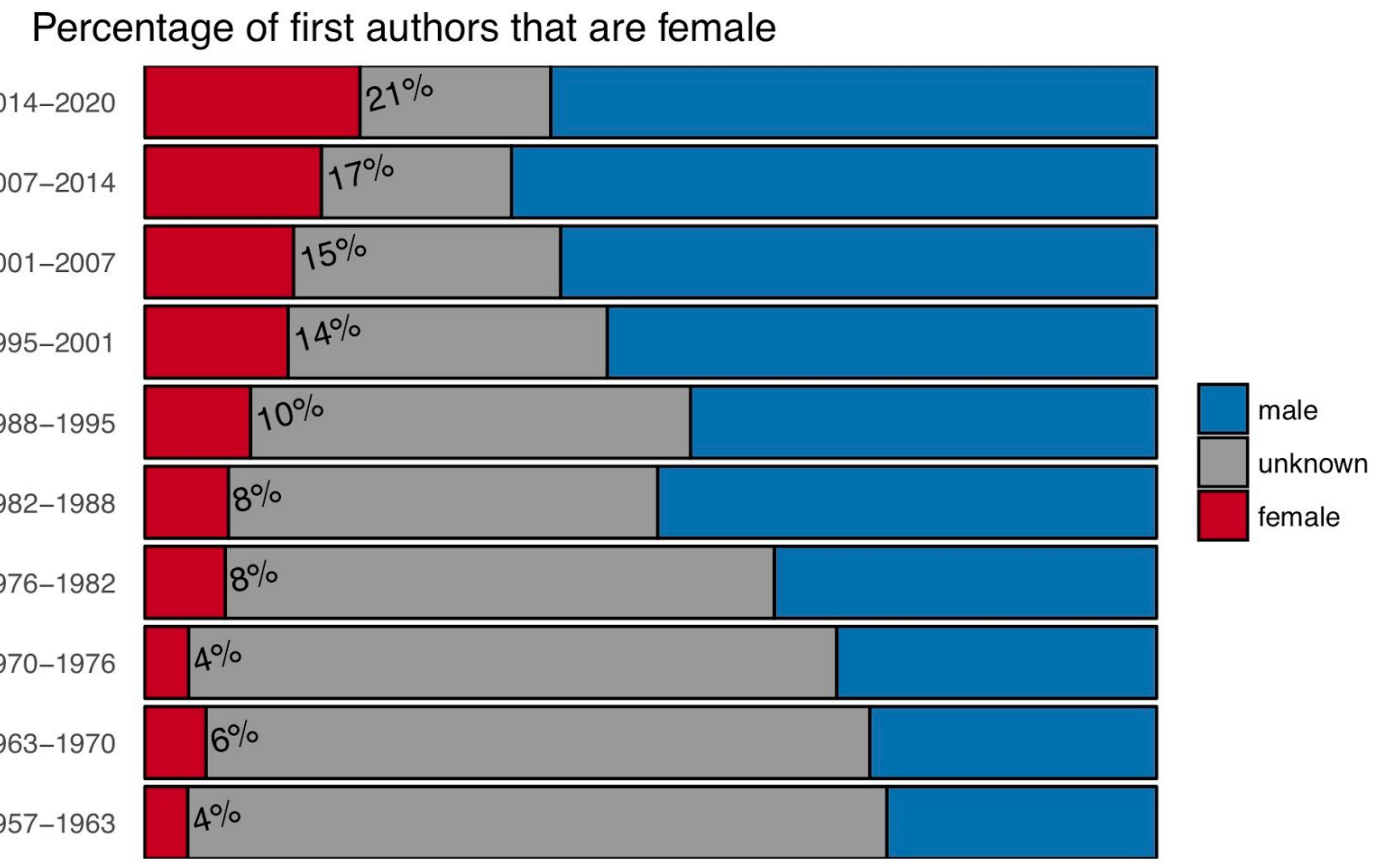

Figure 5. Percentage of male versus female authors that are first authors of articles published in Palaeontology.

\section{The importance of intersectionality}

We emphasize that while this work focuses on gender diversity, there are many aspects of diversity, in addition to gender, that must be considered. These aspects (including socioeconomic background, race, sexual orientation, age and disability), however, cannot be determined from name data. The PalAss Diversity Study (together with evidence from other studies, Bernard and Cooperdock 2018) suggest other components of diversity also remain underrepresented in palaeontology, and individuals from underrepresented or minority groups often feel unsupported by the community. It is important to recognize that the intersectionality of more than one underrepresented identity can exacerbate the challenges of succeeding in academia (Crenshaw 1990), including within the Earth sciences ${ }^{12}$ (see also Clancy et al. 2017). We also note that North American and European institutions are hugely overrepresented in the scientific literature ${ }^{13}$.

\section{What next?}

Here, we make four recommendations that can be adopted by anyone involved in academic publishing and palaeontology more broadly:

\footnotetext{
12 <https://www.nature.com/articles/s41561-019-0519-z>

13 <https://www.nature.com/articles/ngeo3026>
} 
Take diversity issues seriously

Research shows that members of overrepresented groups are more likely to be skeptical of studies that highlight diversity issues (Handley et al. 2015), more likely to overestimate social progress (Kraus et al. 2017), and less likely to engage with diversity and inclusion efforts (Rodríguez et al. 2015). One consequence of this is that women and minorities are taking on the burden of trying to tackle diversity issues without the active support of their more advantaged colleagues (Grogan 2019). Substantive change requires engaging the entire scientific community, and broader awareness of discrimination issues and the implicit and unconscious biases that are inherent to us all ${ }^{14}$.

Recruit more women into all levels of academic publishing

Anyone engaged in primary research can invite women to contribute as co-authors and collaborators, both to gain insights from individuals who may be overlooked and to acknowledge their contributions. It is important to be mindful of acknowledging the contributions of others and citing their work where relevant. Authors and editors can recommend or invite more women to review articles. If you are invited to review an article and cannot, identify women in your field and suggest them instead. The Women in Paleontology Directory $^{15}$ may be helpful here if you are struggling to think of individuals, and if you are a woman you can consider adding your name through the online form. At the same time, we should respect an individual's decision to turn down opportunities to contribute or review. Editorial board members should seek to ensure women are well represented among editors. Presently, $<30 \%$ of Palaeontology editors are women (7/25) and, until recently, the Editorial Board comprised $100 \%$ men (4/4). This year, we welcome the appointment of the journal's first female Editorial Board member, Susie Maidment. Interestingly, one study found that biomedical journals with senior female editors have a higher proportion of articles with female first authors (Filardo et al. 2016). We also can look to other organisations for advice and support in identifying effective strategies for tackling diversity issues.

\section{Actively promote individuals from minority and other underrepresented groups}

Beyond academic publishing, we can invite individuals from underrepresented groups to give talks, join working groups and meetings, chair conference sessions, participate in field and outreach work, participate in the grant application and review processes and nominate individuals for awards. Notably, women are more likely to be invited to give colloquium talks when women are among the organisers (Nittrouer et al. 2018). For conference organisers, 500 Women Scientists recently produced a guide for diversity and inclusion at scientific

\footnotetext{
${ }^{14}<$ https://royalsociety.org/topics-policy/publications/2015/unconscious-bias/>

15 <https://docs.google.com/spreadsheets/d/1c9HUR13HiCpFLy02FKKWPyQq2DGcwDcoL9r9zKb2dA8/edit\#gid=0>
} 
meetings ${ }^{16}$. We can also take the opportunity to engage with and encourage a diverse range of individuals in the classroom, at conferences, and at other meetings (see Gates et al. 2019 for further examples and suggestions).

\section{Collect relevant data and different perspectives}

Keeping track of relevant data to monitor the participation of individuals involved at different levels and in different aspects of palaeontology (e.g. publishing, teaching, conferences) will make a huge difference. If data for past events does not exist or is unavailable in a format that is easy to use, changes can be made to ensure that information can be collected in a useable format in the future. For example, Butler and Maidment were able to examine career prospects in palaeontology using available data to track individuals over time ${ }^{3}$.

Quantitative data, such as that presented here, is extremely valuable for highlighting and monitoring participation in science, but does not provide a complete picture. In particular, it remains challenging to understand the reasons that some groups remain underrepresented in palaeontology. To gain a better understanding, we can look to published research on the barriers to inclusion, and we should continually engage with individuals from different backgrounds. Listening to and promoting the perspectives of others is another way of collecting and disseminating information that will be useful in diversifying our field.

PalAss are committed to increasing diversity within palaeontology. Following the PalAss Diversity Study, initial steps have included the creation of a Diversity Officer role and a Diversity Group on council, the introduction of a carers bursary to assist parents and carers attending the Annual Meeting, and the initiation of a mentoring scheme. We will also continue to monitor available data and present perspectives in the Newsletter.

If you have any ideas or would like to see a particular aspect of diversity discussed in the Newsletter please contact diversity@palass or newsletter@palass.

\section{Acknowledgements}

We thank Freya Johnson Ross, Jana Huisman, Lee Hsiang Liow and Andrew Smith for feedback on the article.

Rachel Warnock

ETH Zurich

University of Zurich

\section{Emma Dunne}

University of Birmingham
Sam Giles

University of Oxford

University of Birmingham

\footnotetext{
16 <https://500womenscientists.org/inclusive-scientific-meetings>
} 
Erin Saupe

University of Oxford
Laura Soul

Smithsonian Institution
Graeme Lloyd

University of Leeds

\section{REFERENCES}

BERENBAUM, M. R. 2019. Speaking of gender bias. PNAS, 116(17), 8086-8088.

BENDELS, M.H., MÜLlER, R., BRUEGgMANN, D. and GRONEBERG, D.A., 2018. Gender disparities in high-quality research revealed by Nature Index journals. PloS One, 13(1), p.e0189136.

BERNARD, R.E. and COOPERDOCK, E.H.G. 2018. No progress on diversity in 40 years. Nature Geoscience, 11(5), 292-295.

CLANCY, K.B., LEE, K.M., RODGERS, E.M. and RICHEY, C. 2017. Double jeopardy in astronomy and planetary science: Women of color face greater risks of gendered and racial harassment. Journal of Geophysical Research: Planets, 122(7), 1610-1623.

CRENSHAW, K., 1990. Mapping the margins: Intersectionality, identity politics, and violence against women of color. Stanford Law Review, 43, 1241-1299.

FILARDO, G., DA GRACA, B., SASS, D.M., POLLOCK, B.D., SMITH, E.B. and MARTINEZ, M.A.M. 2016. Trends and comparison of female first authorship in high impact medical journals: observational study (1994-2014). BMJ, 352, i847.

FINE, C., and SOJO, V. 2019. Women's value: beyond the business case for diversity and inclusion. The Lancet, 393(10171), 515-516.

FONG, E.A. and WILHITE, A.W., 2017. Authorship and citation manipulation in academic research. PloS One, 12(12), 0187394.

FOX, C.W. and PAINE, C.T., 2019. Gender differences in peer review outcomes and manuscript impact at six journals of ecology and evolution. Ecology and Evolution.

GATES, A E., MCNEAL, K., RIGGS, E., SULLIVAN, S., and DALBOTTEN, D. 2019. New developments in diversity and inclusiveness in geosciences. Journal of Geoscience Education, 67(4), 285-286.

GROGAN, K.E., 2019. How the entire scientific community can confront gender bias in the workplace. Nature Ecology \& Evolution, 3(1), 3.

GUARINO, C. M., and BORDEN, V. M. 2017. Faculty service loads and gender: Are women taking care of the academic family? Research in Higher Education, 58(6), 672-694.

HANDLEY, I.M., BROWN, E.R., MOSS-RACUSIN, C.A. and SMITH, J.L., 2015. Quality of evidence revealing subtle gender biases in science is in the eye of the beholder. PNAS, 112(43), 13201-13206.

HENGEL, E. 2017. Publishing while Female. Are women held to higher standards? Evidence from peer review. Cambridge Working Paper Economics, 1753.

HOLMAN L., STUART-FOX D., HAUSER CE (2018) The gender gap in science: How long until women are equally represented? PLoS Biol 16(4): e2004956. 
KING, M.M., BERGSTROM C.T., CORRELL S.J., JACQUET J., WEST J.D. (2017) Men set their own cites high: Gender and self-citation across fields and over time. Socius, 3: 2378023117738903.

KRAUS, M.W., RUCKER, J.M. and RICHESON, J.A., 2017. Americans misperceive racial economic equality. PNAS, 114(39), 10324-10331.

LARIVIÈRE, V., NI, C., GINGRAS, Y., CRONIN, B. and SUGIMOTO, C.R., 2013. Bibliometrics: Global gender disparities in science. Nature News, 504(7479), 211.

LERBACK, J. and HANSON, B., 2017. Journals invite too few women to referee. Nature News, 541(7638), 455.

MAYER, S.J. and RATHMANN, J.M., 2018. How does research productivity relate to gender? Analyzing gender differences for multiple publication dimensions. Scientometrics, 117(3), 1663-1693.

NITTROUER, C.L., HEBL, M.R., ASHBURN-NARDO, L., TRUMP-STEELE, R.C., Lane, D.M. and Valian, V., 2018. Gender disparities in colloquium speakers at top universities. PNAS, 115(1), 104-108.

RODRÍGUEZ, J.E., CAMPBELL, K.M. and POLOLI, L.H., 2015. Addressing disparities in academic medicine: what of the minority tax? BMC Medical Education, 15(1), 6.

SERIO, T., 2016. Speak up about subtle sexism in science. Nature News, 532(7600), 415.

SHEN, Y.A., SHODA, Y. and FINE, I., 2018. Too few women authors on research papers in leading journals. Nature, 555(7695). 